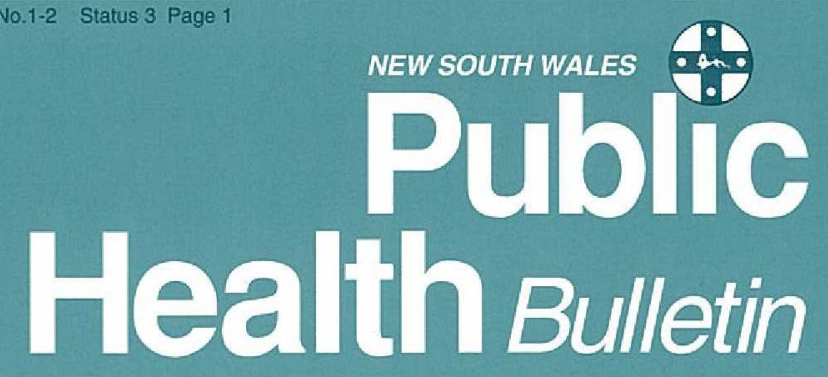

\section{HePATITIS A OUTBREAK TRACED TO CONSUMPTION OF WALLIS LAKE OYSTERS}

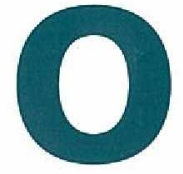

n Monday, February 10, 1997 the AIDS/Infectious Diseases Branch of the NSW Health Department received from South West Sydney Public Health Unit reports of four cases of hepatitis A. Three of these cases had travelled to the mid-north coast of NSW and two reported having consumed oysters while there. All Public Health Units in NSW were asked to initiate active surveillance for hepatitis A, and to inquire from cases about history of travel and food consumption. Eighteen notifications were received on February 10 , and 150 cases had been notified by Friday, February 14 with an onset after January 21 . This preliminary report outlines an ongoing investigation of this outbreak that has involved staff of Public Health Units, laboratories, general practitioners, the Department of Fisheries, the Environment Protection Authority, local councils, oyster growers, patients, and the NSW Health Department's Epidemiology and Surveillance, Environmental Health, Food and Nutrition and AIDS/Infectious Diseases Branches.

\section{EPIDEMIOLOGY AND CLINICAL FEATURES OF HEPATITIS A}

Hepatitis A virus is a small RNA virus from the genus picornaviradae ${ }^{1}$. It is resistant to many disinfection techniques, is commonly found in sewage, and may persist in the environment for weeks. Infection is by the faecal-oral route. After an incubation period of 2-6 weeks, infection causes a 1-2 week illness characterised by fever, malaise, anorexia, nausea and abdominal pain, followed by jaundice. The virus is shed in the faeces late in the incubation period and during the symptomatic stages of the illness. Viral shedding peaks with onset of jaundice and becomes negligible probably a week after this. The usual mode of spread is person-to-person, and is facilitated by poor hygiene and sanitation.

The disease is often mild or unnoticed in children but is more severe in adults. Overall mortality is less than 1 per cent, but is reported to be as high as 2.7 per cent in people aged $>50$ years ${ }^{2}$. Point source outbreaks linked to infected food handlers or consumption of sewage-contaminated shellfish - particularly oysters - are well described ${ }^{3}$. Immunity to hepatitis A after natural infection is common and lifelong. Improved levels of sanitation in developed countries have led to a large proportion of the population escaping mild childhood disease, but paradoxically have increased the likelihood of severe disease later in adult life.

\section{THE INVESTIGATION}

Early interviews with cases indicated that some had eaten oysters bought from the mid-north coast of NSW. When we interviewed the cases using a standard questionnaire, we found that more than 70 per cent reported eating oysters during the incubation period. A matched case-control study on February 14 showed a strong association between illness and consumption of oysters

\section{Contents}

\section{Articles}

1 Hepatitis A outbreak traced to Wallis

Lake oysters

2 The Hepatitis $C$ Lookback Project

4 The NSW Public Health Officer Training Program placements, 1997

5 Method for Evaluating Research and Guideline Evidence

\section{Infectious Diseases}

\section{Correspondence}

Please address all correspondence and potential contributions to:

The Editor;

NSW Public Health Bulletin, Public Healtb Division, NSW Health Department Locked Bag No 961, North Sydney NSW 2059 Telephone: (02) 93919191

Facsimile: (02) 93919029 


\section{MethOd FOR EVALUATING ReSEARCH AND GUIDELINE EVIDENCE}

Jeannine Liddle,

Centre for Clinical Policy and Practice

$\mathrm{T}$ he NSW Health Department has published a monograph entitled Method for Evaluating Research and Guideline Evidence (MERGE)1. The monograph sets out a standardised approach to the process of reviewing and incorporating scientific evidence into clinical practice guidelines. MERGE is intended to assist in the application of principles for the development of guidelines, as proposed by the National Health and Medical Research Council's Quality of Care and Health Outcomes Committee. These principles are:
- Clinical practice guidelines should be based on the best available evidence.
口 The method used to synthesise the evidence should be the strongest available.
口 Guidelines should contain a statement concerning the strength of evidence ${ }^{2}$.

MERGE was written with input from epidemiologists working in Australia, the Cochrane Collaboration and clinician members of the NSW Health Department's Expert Panel on Diabetes Guidelines Working Group. The monograph consists of a series of checklists for evaluating the quality of evidence both from individual studies and intervention guidelines. It includes examples related to the management of diabetes.

Copies of MERGE can be obtained from the Better Health Centre, 162 Blues Point Road, North Sydney, NSW 2060. Facsimile: (02) 9955 5196, telephone: (02) 99541193.

MERGE is also available on the NSW Health Department website: http://www.health.nsw.au/public health

1. Liddle J. Williamson M, Irwig L. Method for Evaluating Research and Guideline Evidence. NSW Health Department, Sydney, December 1996. 2. NHMRC Quality of Care and Health Outcomes Committee. Guidelines for the development and implementation of clinical practice guidelines. Australian Government Publishing Service, Canberra, October 1995.

\section{Hepatitis A outbreak}

\section{Continued from page 1}

(unadjusted matched odds ratio $7, \mathrm{p}<0.001$ ). In the great majority of instances where the source of the oysters was known, it was Wallis Lake. That day, a public warning was issued, linking the outbreak to consumption of Wallis Lake oysters. In collaboration with the oyster industry and other government departments, harvesting of these oysters was ceased and steps towards a voluntary recall of the product were begun.

As of March 9, 1997, we had received more than 370 notifications of hepatitis A cases with onset after January 21 (almost four times the number expected for this time of year). Over a similar period, excess cases were also recorded in Queensland, South Australia, Victoria and the Australian Capital Territory. One death - that of a man aged 77 years - has been attributed to the epidemic. The peak reported date of onset was February 3 (28 cases), and the peak reported date of oyster purchase among cases who ate oysters on a single occasion during their incubation period was January 4 . Hepatitis A virus was identified by polymerase chain reaction amplification (PCR) techniques in a batch of oysters taken from a Wallis Lake oyster lease on February 18.
Wallis Lake (one of the estuarine Great Lakes on the mid-north coast of NSW, in the Forster-Tuncurry area) is one of the largest oyster growing areas in Australia. During the Christmas and New Year period, the distribution of the Sydney Rock Oyster (the species grown in Wallis Lake) was extensive. An environmental audit of the Lake and environs is in progress. An inter-Departmental task force, chaired by the Chief Health Officer, is working on the definition of criteria to be fulfilled before the lake can be reopened for oyster harvesting.

A more complete report of the outbreak investigation will appear in a future issue of the NSW Public Health Bulletin.

1. Melnick JL. History and Epidemiology of Hepatitis A virus. JID 1995; 171(suppl 1):S2-8.

2. Benenson AS (Ed). Control of Communicable Diseases Manual (16th Edition). American Public Health Association.

3. Desenclos JA, Klontz KC, Wilder $\mathrm{MH}$ et al. A multistate outbreak of hepatitis A caused by the consumption of raw oysters. Am J Public Health 1991; 81:1268-1272. 